\title{
Asutenite Retention in low Al/Si multiphase steels
}

\author{
T. De Cock, J.P. Ferrer, C. Capdevila, F.G. Caballero, V. López and C. García de \\ Andrés \\ Solid-Solid Phase Transformation Group (Materalia) \\ Department of Physical Metallurgy, Centro Nacional de Investigaciones Metalúrgicas \\ (CENIM), Consejo Superior de Investigaciones Científicas (CSIC), Avda. Gregorio del \\ Amo, 8, E-28040 Madrid, Spain
}

Keywords: TRIP steels, retained austenite, metallography, mechanical properties

\begin{abstract}
The possibility to obtain multiphase steels with considerable fractions of retained austenite, which is of key interest for the occurrence of the TRIP effect, is investigated in steels with low amounts of $\mathrm{Si}$ and Al. Special emphasis is dedicated to the microstructural observation of this phase, since its volume fraction, distribution and stability, related to the carbon content, will determine the efficiency of the TRIP effect and thus of the resulting mechanical properties. In this sense, some mechanical testing was carried out in order to measure the efficiency of the retained austenite to transform to marten site.
\end{abstract}

\section{Introduction}

Economical and ecological considerations as well as safety-related requirements drive the automotive industry towards the production of light-weigth components with enhanced mechanical properties. Therefore, one of the main challenges of th is sector is to produce high stren gth steels without deteriorating the formability of the material.

In this context, the development of TRIP-assisted steels is a significant step in this direction. These steels present a complex microstructure which consists of ductile ferrite, ultra-high strength martensite, bainite and austenite. The austenite phase is metastable at room temperature and transforms to martensite during straining, bringing about the so called TRIP effect (transformation-induced plasticity) [1]. It is known that this phenomenon drastically improves the balance between strength and ductility in a large amount of ferrous alloys ranging from fully austenitic stainless steels [2] to quenched and tempered martensitic steels with a fine dispersion of retained austenite [3].

In the late eighties it was demonstrated that some dispersed austenite may also be obtained as the result of an intercritical annealing treatment followed by austempering at the bainite forming temperature [4]. This two-step heat treatment yields highperformance TRIP-assisted steels, since the retained austenite is successively carbon enriched for its thermal stabilization at room temperature. To avoid carbide precipitation in the austenite during the bain itic transformation stage the steel is usually alloyed with elements such as $\mathrm{Si}, \mathrm{Al}$ and $\mathrm{P}$. However, the contents of the se elements (typically higher than $1,5 \mathrm{wt}-\%$ ) are often too high for industrial practice [5]. It is the goal of this work to study the feasibility to obtain low $\mathrm{Al} / \mathrm{Si}$ multiphase steels with appreciable amounts of retained austenite. 


\section{Materials and experimental Techniques}

The steel used for this study is a medium carbon forging steel with the following composition:

Table 1. Composition of the studied steel (in wt.-\%)

\begin{tabular}{cccccccc}
\hline $\mathrm{C}$ & $\mathrm{Mn}$ & $\mathrm{Si}$ & $\mathrm{P}$ & $\mathrm{S}$ & $\mathrm{Cr}$ & $\mathrm{Al}$ & $\mathrm{Cu}$ \\
\hline 0.20 & 1.1 & 0.34 & 0.010 & 0.011 & 0.011 & 0.036 & 0.018
\end{tabular}

Small cylindrical samples were cut out from a hot rolled strip and subsequently a twostep heat treatment has been applied to the samples: during the first stage (in the ferriteaustenite range) the samples were heated $\left(20^{\circ} \mathrm{C} / \mathrm{s}\right)$ up to an intercritical annealing stage of 5 minutes duration in the temperature range between 720 and $800^{\circ} \mathrm{C}$. A sufficiently high cooling rate $\left(50^{\circ} \mathrm{C} / \mathrm{s}\right)$ avoids the formation of pearlite during cooling after this stage. At the second holding stage, at temperatures between 300 and $450^{\circ} \mathrm{C}$ and for times varying between 0 and 600s, a bainitic transformation may occur. Figure 1 shows the applied thermal treaments, to gether with the conditions of both holding stages.

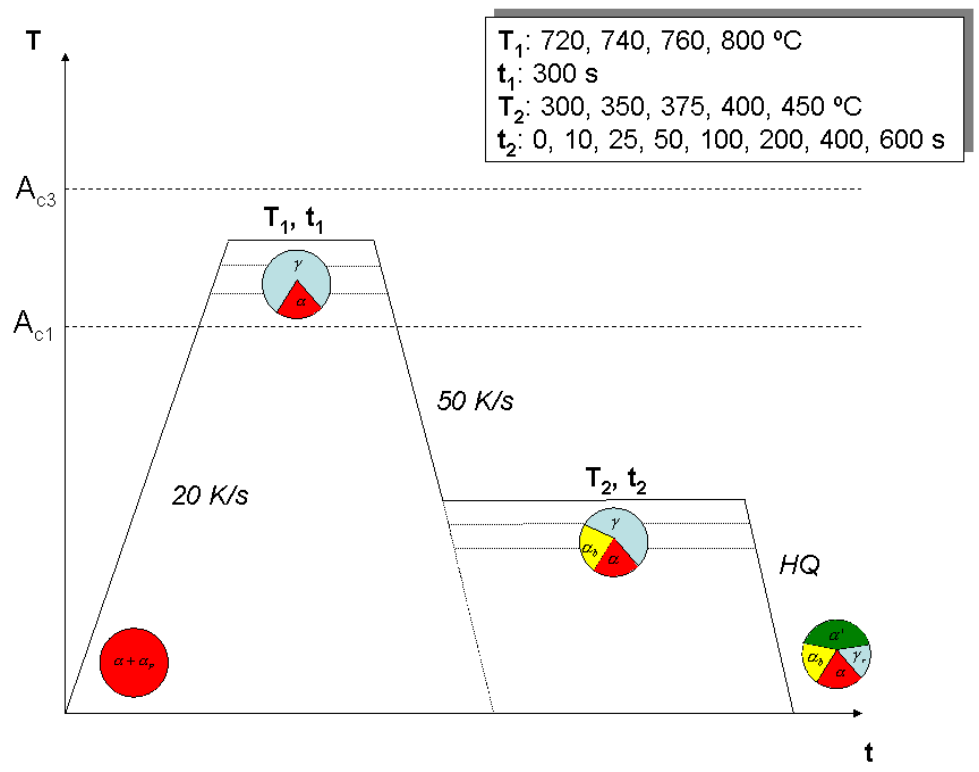

Fig. 1. Applied thermal path for the production of multiphase steels. $\alpha$ : ferrite; $\alpha_{\mathrm{p}}$; pearlite; $\gamma$ : austenite; $\alpha_{b}$ : bainite; $\alpha^{\prime}$ : martensite; $\gamma_{r}$ : retained austenite; HQ: helium quench.

The samples were then mounted in bakelite for metallographic examination and subsequently grounded and polished according to standardized techniques. The different metallographic techniques to reveal the microstructure of the samples will be discussed further on. From these observations the most promising samples were selected for detailed examination with field-emission electron microscopy (FEG-SEM). X-Ray diffraction (XRD) measurements were carried out to measure the retained austenite content by means of the Schulz reflection method, using a D-5000 X-ray diffractometer furnished with an opened Eulerian cradle. Details of the diffractometer used are given 
elsewhere [6], whereas the experimental method to measure the retained austenite fraction with XRD is explained in [7].

\section{Results and Discussion}

\section{a. Determination of the retained austenite content}

As was mentioned above, the presence of retained austenite at room temperature, as well as its stability, are key factors for the occurrence of a TRIP effect during the subsequent forming process. Therefore, a reliable and efficient way to determine the fraction of retained austenite is of major interest.

A first colour etching procedure, with the well known LePera reagent [8], was carried out to distinguish the ferrite, bainite and martensite/austenite phases. A typical micrograph of a multiphase microstructure etched with this reagent is shown in Fig. 3(a). A major drawback of this etchant is that it does not allow the distinction between martensite and austenite [9], and so an additional etching technique must be applied. It was found that an etching procedure, based on the observations of De et al. [10] and which consists of a first 2\% nital etch (10 s) followed by a second etch with $10 \%$ aqueous sodium metabisulfite $(30 \mathrm{~s})$ allows the observation of the retained austenite when observed with a blue color filter [11], as shown in Fig. 3(b). This technique requires a higher magnification in order to disclose the presence of retained austenite in the microstructure.

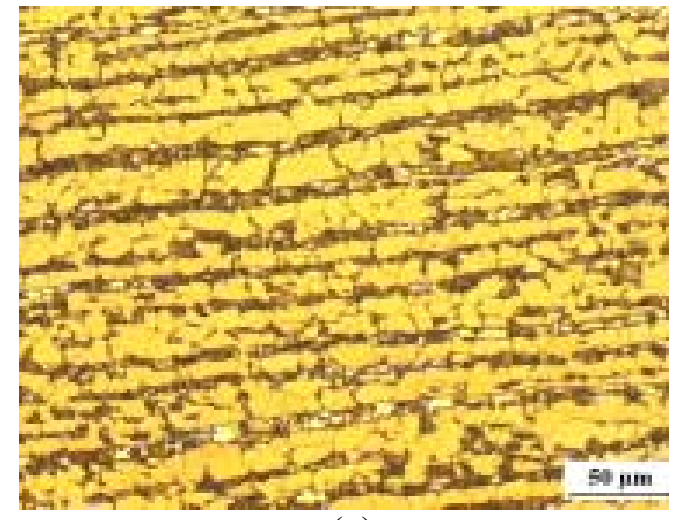

(a)

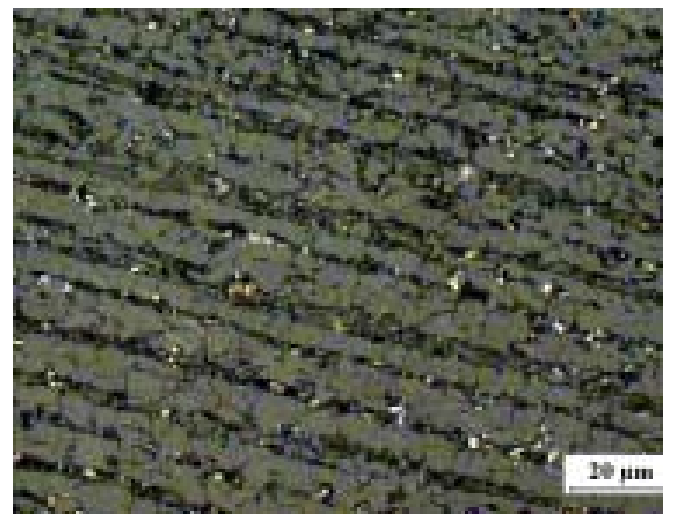

(b)

Fig. 2. (a) LePera etching of a multiphase sample. Dark zones correspond to bain ite, clear zones are ferritic and the white spots are martensite or retained austenite. (b) Nital + sodium metabisulfite etching viewed with blue color filter. The white spots correspond to retained austenite.

To check if the fraction of retained austenite $\left(\gamma_{\mathrm{r}}\right)$ measured with the described metallographic method is actually corresponding to the real fraction of this phase, X-ray diffraction analysis was carried out on two of the most promising samples. Details of these measurements are listed in Table 2.

Table 2. Comparison of two methods for the quantification of the retained austenite fraction

\begin{tabular}{ccccc}
\hline $\mathrm{T}_{1}$ & $\mathrm{~T}_{2}$ & $\mathrm{t}_{2}$ & $\begin{array}{c}\gamma_{\mathrm{r}} \\
\text { (metallography) }\end{array}$ & $\begin{array}{c}\gamma_{\mathrm{r}} \\
(\mathrm{XRD})\end{array}$ \\
\hline $740^{\circ} \mathrm{C}$ & $375^{\circ} \mathrm{C}$ & $200 \mathrm{~s}$ & $3.85 \%$ & $4.0 \pm 0.5 \%$ \\
\hline
\end{tabular}




\begin{tabular}{lllll}
\hline $740^{\circ} \mathrm{C}$ & $300^{\circ} \mathrm{C}$ & $200 \mathrm{~s}$ & $5.33 \%$ & $4.6 \pm 0.4 \%$ \\
\hline
\end{tabular}

It can be clearly seen that there is a good relation between both methods for the quantification of the fraction of the retained austenite.

\section{b. Influence of two-step heat treatment parameters}

Firstly, the influence of the intercritical annealing temperature has been investigated. It is clear that an intermediate temperature $T_{1}$ is recommended, since at high intercritical temperature a high fraction of residual austenite is formed with low stability, whereas at low temperatures the fraction of austenite formed may be too low to retain any of this phase at room temperature. It is found that $\mathrm{T}_{1}=740^{\circ} \mathrm{C}$ is a suitable intercritical holding temperature for the present steel.

Fig, 3 shows the retained austenite content at all bainitic holding conditions studies for prior intercritical annealing at $740^{\circ} \mathrm{C}$. It can be clearly seen that, in order to maximise this content, a balance must be reached between both parameters.

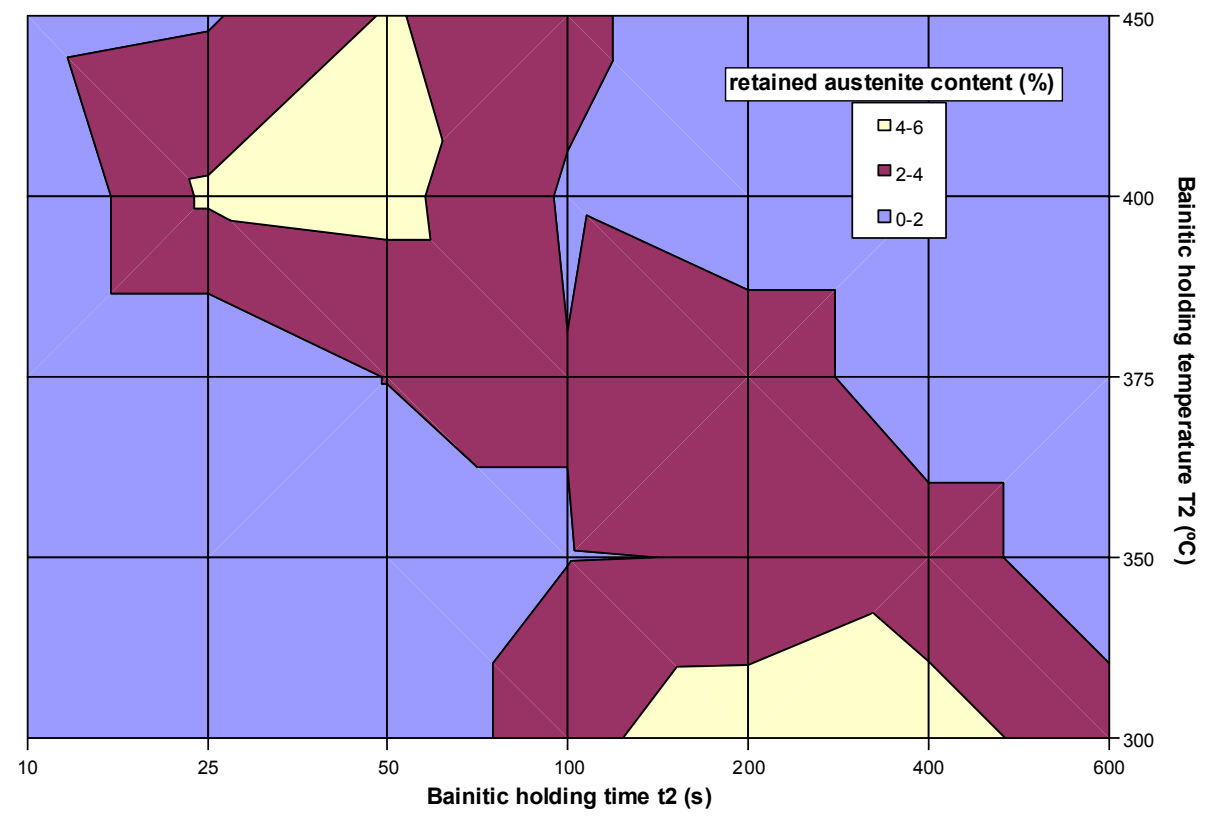

Fig. 3. Evolution of the retained austenite fraction in function of bainitic holding time and temperat ure at the intercritic al holding temperature of $740^{\circ} \mathrm{C}$.

In order to explain this observation transformations maps can be drawn for the different conditions of the heat treatment. As an example the maps for intercritical temperature $\mathrm{T}_{1}=740^{\circ} \mathrm{C}$ are given in Fig. 4 for the case of high bainitic holding temperature $\left(\mathrm{T}_{2}=400^{\circ} \mathrm{C}\right.$; fig. $\left.4(\mathrm{a})\right)$ and lower bainitic holding temperature $\left(\mathrm{T}_{2}=350^{\circ} \mathrm{C}\right.$; fig. $\left.4(\mathrm{~b})\right)$.

These transformation maps clearly show the influence of the bainitic holding temperature $\left(\mathrm{T}_{2}\right)$ and time $\left(\mathrm{t}_{2}\right)$ on the microstructure of the studied steel. It has been extensively reported that the formation of bainite is accompanied by a carbon enrichment of the residual austenite. As can be seen in Fig. 4(a), at low bainitic holding times this enrichment is not sufficient to stabilise the austenite and the austenite transforms almost completely to martensite after rapid cooling. At higher times $t_{2}$ the 
austenite is gradually stabilised during the formation of bainite. Due to the so called 'incomplete reaction phenomenon' [12] part of the austenite will not transform to bainite and if the carbon content of the residual austenite is sufficiently elevated it will remain untransformed after cooling to room temperature. This way the fraction of retained austenite increases at the expenses of martensite. At even higher holding times carbide precipitation in the austenite takes place and the retained austenite fraction lowers again. At lower bainitic holding temperatures similar conclusions can be drawn. The main difference in this case is that the diffusion of carbon into the austenite is a slower process and the austenite is thus stabilised at higher holding times.

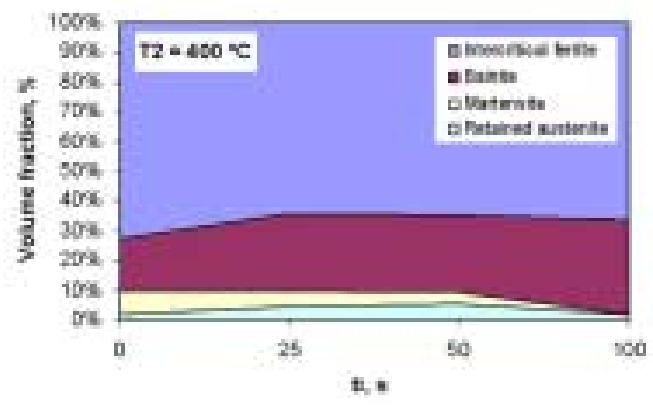

(a)

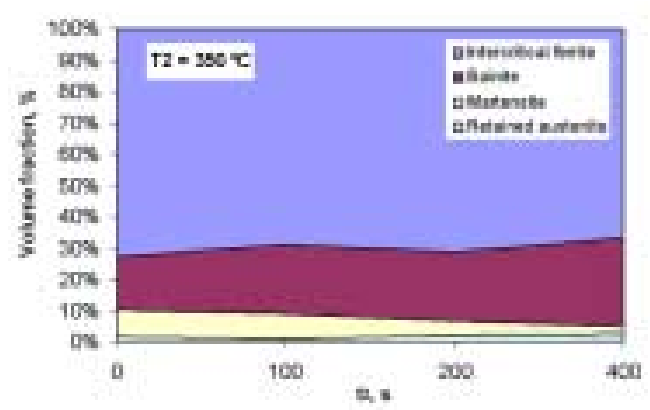

(b)

Fig. 4. Transformation diagram of the sample with $\mathrm{T}_{1}=740^{\circ} \mathrm{C}$ and (a) high bainitic hold ing temperature $\left(\mathrm{T}_{2}=400^{\circ} \mathrm{C}\right)$ and (b) low bainitic holding temperature $\left(\mathrm{T}_{2}=350^{\circ} \mathrm{C}\right)$.

Some of the above samples were also studied with FEG-SEM for a more detailed view of the microstructure. As can be seen in Fig. 5 the different phases can be clearly observed, even though it is impossible to distinguish between martensite and retained austenite. In some microstructures pearlite formation was not inhibited completely.

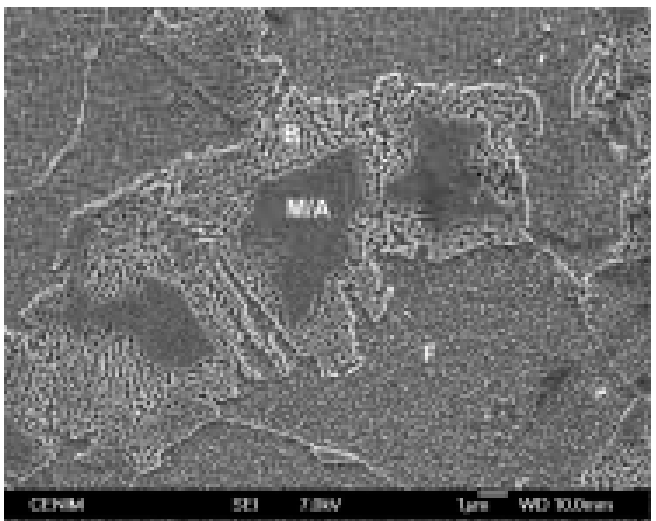

Fig. 5. FEG-SEM image of the of the sample intercritically annealed at $740^{\circ} \mathrm{C}$ and held at bain it ic holding temperature of $400^{\circ} \mathrm{C}$ during $25 \mathrm{~s}$, indicating the ferrite (F), bain ite (B) and martensite (M) / austenite (A) phases.

\section{c. Mechanical stability of the retained austenite}


Finally, a validation of the mechanical stability of the retained austenite has been carried out. In order to study the presence of a TRIP effect in the steel with a remarkable retained austenite content, the second steel in Table 2 was selected and mechanised. Subsequently, a tensile test was carried out and the fraction of austenite was measured with XRD, both before and after the mechanical testing. The work hardening behaviour was described using the change in the instantaneous work hardening exponent $n$ defined as the following equation evaluated from the true-stress true-strain curve:

$\mathrm{n}=\mathrm{d} \sigma / \mathrm{d} \varepsilon$

where $\sigma$ is the true stress and $\varepsilon$ is the true strain. Results of the mechanical test are showed in Figure 6. The retained austenite measured after the deformation was $2.2 \% \pm$ 0.3 , which suggests that some of the retained austenite transformed to martensite during the deformation. This effect, together with the behaviour of the work hardening exponent, characterised by a plateau prior to fracture with $\mathrm{n}>1000 \mathrm{MPa}$, indicate that a TRIP effect may have taken place during mechanical testing [14,15].

The results accomplished involve not only that austenite can be retained in lowaluminium - low-silicon steels, but also that the amount and distribution of austenite achieved is suitable for the occurrence of a TRIP effect.

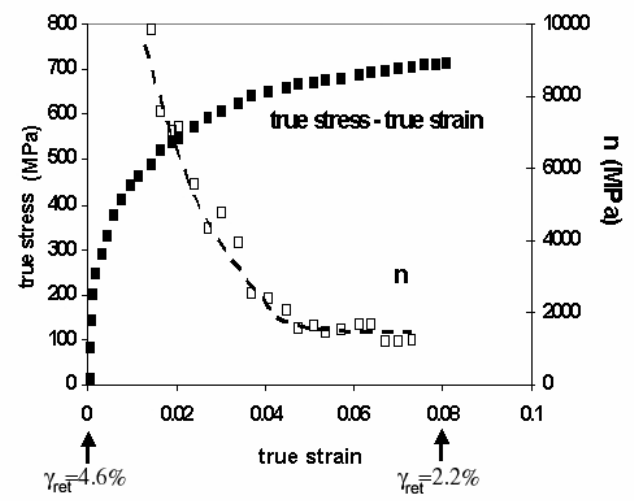

Fig. 6. True-stress true strain curve and work hardening behaviour of the treated sample.

\section{Conclusions}

A complete series of two-step heat treatments has been carried out to find the optimum conditions for the retention of austenite in a low $\mathrm{Al} / \mathrm{Si}$ medium carbon forging steel. At intermediate intercritical holding temperatures $\left(740^{\circ} \mathrm{C}\right.$ approximately) and bainitic hold ing temperatures between 300 and $400^{\circ} \mathrm{C}$ fractions of retained austenite have been observed of approximately $6 \%$. Two different methods have been proposed to quantify this fraction accurately. The mechanical behaviour of one of most promising samples, in view of the high retained austenite content, together with the drop of retained austenite after testing suggest that the sample is capable of provoking a TRIP effect. 


\section{Acknowledgements}

The authors acknowledge financial support from the European Union through the European Coal and Steel Community programme (ECSC-7210-PR-368) and from the Spanish Ministerio de Educación y Ciencia (Special Action MAT 2002-10810-E). T. De Cock would also like to express his gratitude to the Consejo Superior de Investigaciones Científicas (CSIC) for financial support in the form of a $\mathrm{PhD}$ research grant (I3P program). JP Ferrer would also like to thank the MEC for financial support in the form of a PhD research grant (FPI program).

\section{References}

[1] Zackay VF, Parker ER, Fahr D, Busch R. Trans ASM 1967;60:252.

[2] Spencer K, Embury JD, Conlon KT, Véron M and Bréchet Y. Mat Sc and Eng 2004; 387-389:873.

[3] Haidemenopoulos, GN. Dispersed-phase transformation toughen ing in ultrahighstrength steels. Boston, PhD Thesis. Massachusetts Institute of Technology (USA); 1988.

[4] De Cooman, BC. Curr Op in Solid State Mater Sci 2004;8:285.

[5] Mertens, A. Influence of aluminium on the phase transformations during the heat treatments for the processing of multiphase TRIP-assisted steels. PhD Thesis. Université catholique de Louvain; 2002.

[6] Perez-Prado MT, Ibañez J, Morris M, Cristina MC, Ruano OA and GonzalezDoncel G. Rev Metal Madrid 1998;34:324.

[7] De Meyer M, Vanderschueren D, De Blauwe K, De Cooman BC. The characterisation of retained austenite in TRIP steels by $\mathrm{X}$ ray diffraction. ISS, 41st Mechanical Working and Steel Processing Conference, 24-27/10/99, Baltimore, Vol. XXXXVII.pp. 483-491.

[8] LePera FS. J Metals 1980;32:38.

[9] Girault E, Jacques P, Harlet Ph, Mols K, Van Humbeeck J, Aernoudt E and Delannay F. Mater Char 1998;40:111.

[10] De AK, Speer JG and Matlock DK. Adv Mater Processes 2003;27.

[11] Quantitative phase Analysis of multiphase steels - PHAS T Interim Report, ECSC; 2003.

[12] Bhadeshia HKDH and Edmonds DV. Acta Metall 1980;28:1265.

[13] Bleck W, Papaefthymiou S, Frehn A. Steel Research Intern 2004;75:704.

[14] Bleck W. International Conference on TRIP-aided High Strength Ferrous Alloys, n. Mainz, Aachen: Ed. B.C. De Cooman; 2002. p. 13. 